\title{
MULTIPLE DISEASE ASSOCIATIONS IN AUTOIMMUNE POLYGLANDULAR SYNDROMES
}

Anna M.Dabrowska ${ }^{1}$, Agnieszka Zwolak ${ }^{1,2}$, Jerzy S.Tarach ${ }^{1}$

${ }^{1}$ Chair and Department of Endocrinology, Medical University of Lublin, Poland

${ }^{2}$ Chair of Internal Medicine and Department of Internal Medicine in Nursing, Medical University of Lublin, Poland

INTRODUCTION: Autoimmune polyglandular syndromes (APS) are a heterogeneous group of disorders characterized by autoimmune activity against endocrine and non-endocrine organs. APS type depends on the combination of the diseases (APS1, APS2, APS3).

METHODS: The study was conducted in 89 patients (7OF,19M) with APS aged mean $50.00 \pm 14.80$ years, treated at Endocrinology Department between 2003 and 2015. We analyzed clinical manifestations, results of laboratory tests and imaging to determine the components of APS.

\section{RESULTS}

FIG.1 The prevalence of syndromes in APS

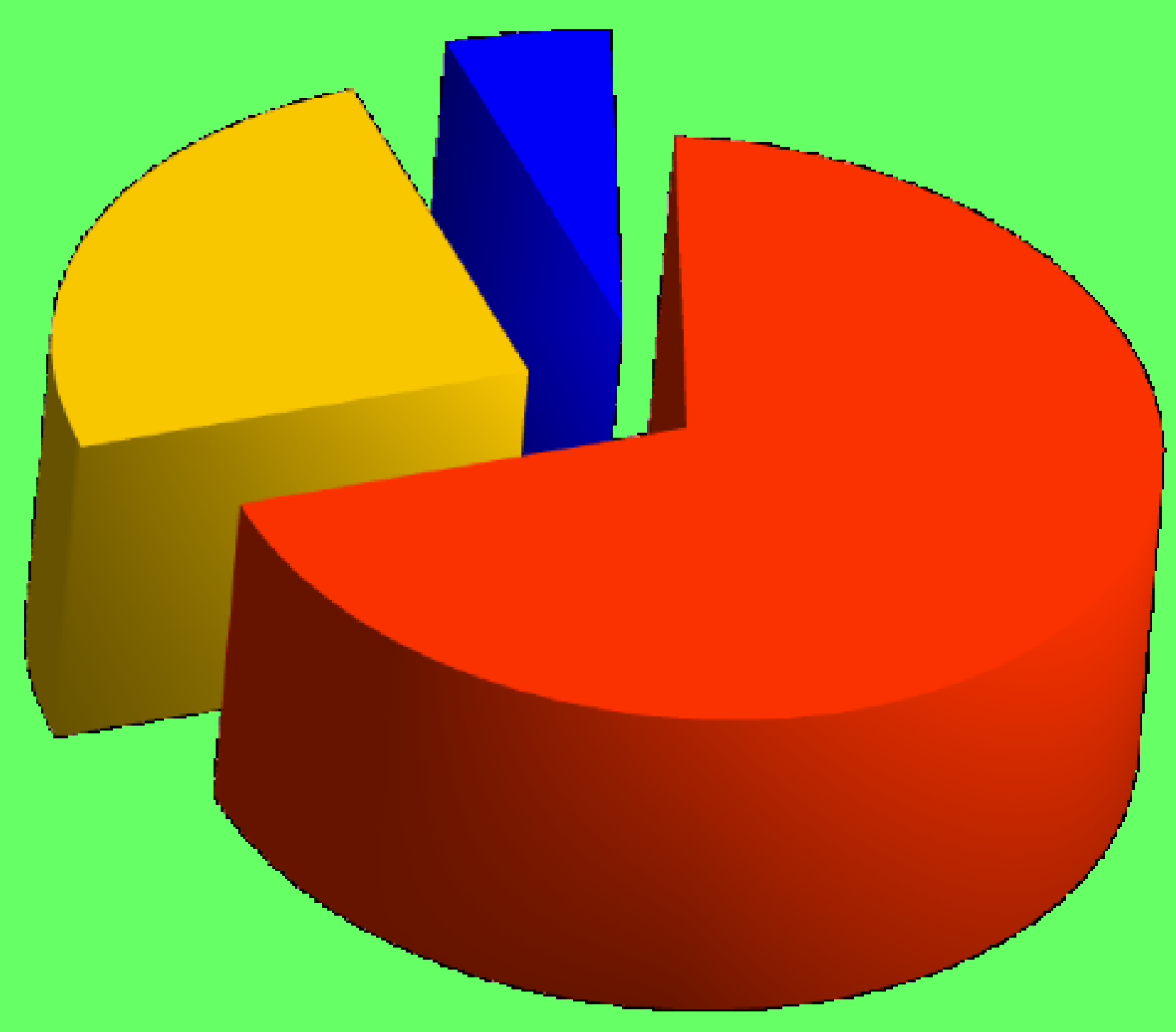

APS $1-5.62 \%$

APS $2-24.72 \%$

APS 3- $69.66 \%$
ATD were found in $84.27 \%$ of all cases with APS and in $100 \%$ with APS1, in $86.36 \%$ with APS2 and in $82.26 \%$ with APS3

FIG 2. Autoimmune thyroid diseases (ATD)

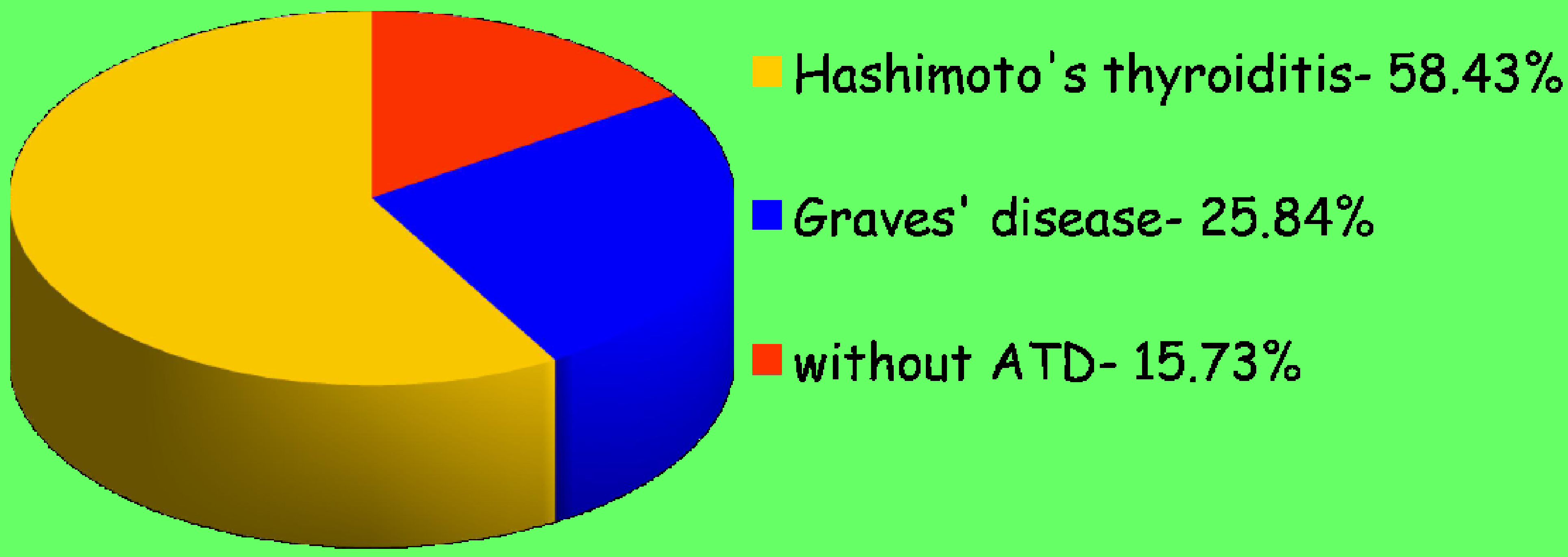

DM1 was diagnosed in $61.80 \%$ of all participants with APS and in $20.00 \%$ with APS1, in $27.27 \%$ with APS2 and in $77.42 \%$ with APS3.

FIG.3 Type 1 diabetes mellitus (DM1)

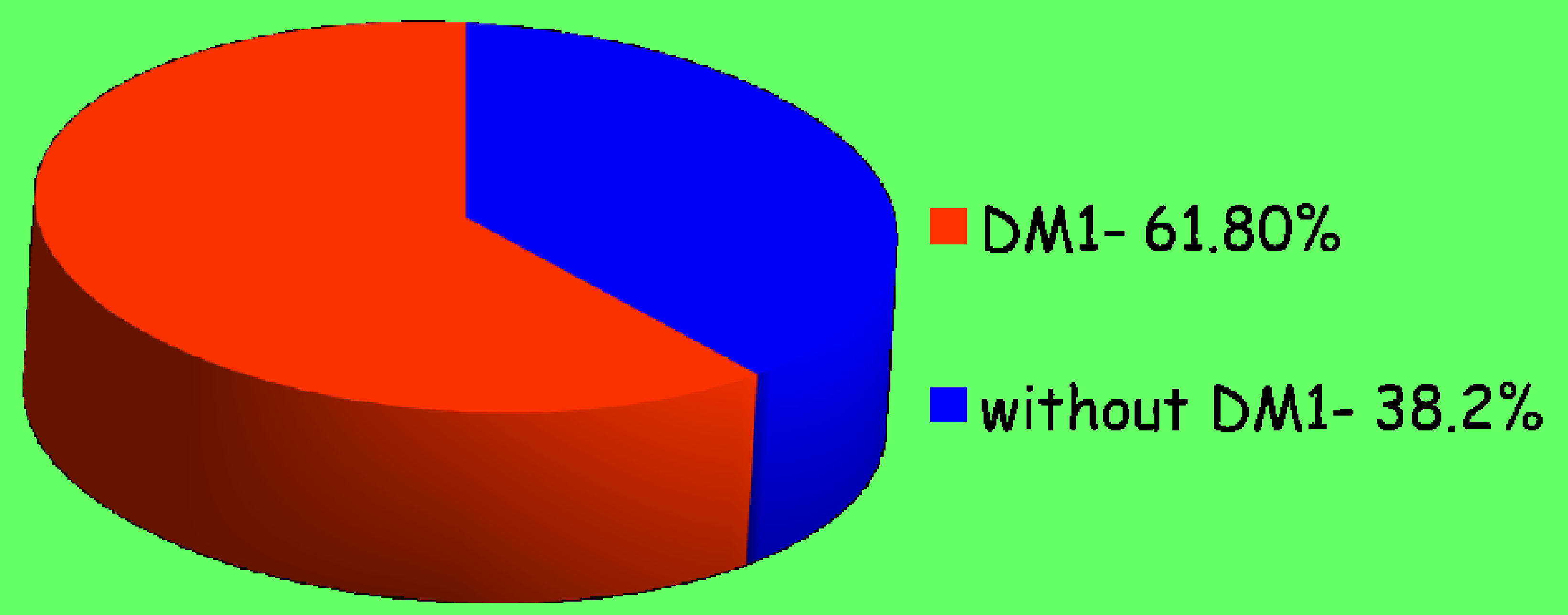

TAB.1 Other diseases in all cases with APS

\begin{tabular}{|c|c|}
\hline Other diseases in APS & $\begin{array}{c}\% \text { of all cases } \\
\text { with APS }\end{array}$ \\
\hline 1. Addison's disease & 29.21 \\
\hline 2. vitiligo & 17.98 \\
\hline 3. psoriasis & 12.36 \\
\hline 4. Addison-Biermer anemia & 10.12 \\
\hline 5. alopecia areata & 5.62 \\
\hline 6. asthma & 3.37 \\
\hline $\begin{array}{l}\text { 7. rheumatoid arthritis, myasthenia } \\
\text { gravis, coeliac disease, ulcerative } \\
\text { colitis, autoimmune hepatitis }\end{array}$ & in individuals \\
\hline
\end{tabular}

- In APS1, 3-6 diseases were noted, mostly the coexistence of Addison's disease and hypoparathyroidism.

- 2-3 diseases were found in APS2. Schmidt's syndrome was determined in $63.64 \%$ of patients with APS2, Carpenter syndrome-only in 2 cases. The most common diseases in APS2 were: Hashimoto's disease, type 1 diabetes, Graves' disease (72.73\%, 27.27\%, $13.64 \%$ respectively).

- In APS3, 2-4 diseases were found. Type 1 diabetes, Hashimoto's disease, Graves' disease were the most common disorders ( $77.42 \%, 50.00 \%$, $32.26 \%$ respectively). The most common coexistence in APS3 was type 1 diabetes with Hashimoto's disease.

CONCLUSIONS: Although some diseases occur more frequently than others, it should be remembered about various APS components during follow-up such patients.

$17^{\text {th }}$ European Congress of Endocrinology, 16-20.05.2015 DUBLIN 